\title{
RECURSOS, CONTROLE E AUTONOMIA NA GESTÃO INTERNACIONAL DE SERVIÇOS DE UMA EMPRESA DE TI E SUBSIDIÁRIAS
}

\section{RESOURCES, CONTROL AND AUTONOMY IN INTERNATIONAL SERVICES MANAGEMENT OF IT COMPANY AND SUBSIDIARIES}

RECURSOS, CONTROL Y AUTONOMIÍA EN LA GESTIÓN INTERNACIONAL DE SERVICIOS DE UNA EMPRESA DE TI Y SUBSIDIARIAS

\section{RESUMO}

Este estudo analisa as características da Gestão de Serviços Globalmente Integrada (GSGI) de uma multinacional de tecnologia de informação e subsidiárias. O estudo também explora: 1) como a matriz gerencia os recursos e lida com o paradoxo do controle e autonomia das subsidiárias e 2) algumas diferenças entre a GSGI e outros modelos de gestão internacionais: exportação de serviços, multinacionais e transnacionais. Para realizar a pesquisa, foi acompanhada a implantação da GSGI na matriz e subsidiária de uma empresa do setor de tec-

nologia da informação. A metodologia da pesquisa é qualitativa, descritiva e exploratória, realizada por meio de um estudo de caso na matriz e subsidiária. A coleta de dados foi por meio de entrevistas realizada com 25 executivos da matriz americana e da subsidiária brasileira. Os resultados revelam que a adoção da GSGI gera um relativo aproveitamento dos recursos, estimulando competências locais, e ainda combina mecanismos de controle da matriz com a autonomia e independência das subsidiárias.

PALAVRAS-CHAVE Gestão de serviços globalmente integrada, modelos de internacionalização, tecnologia de informação, redes de subsidiárias, recursos e autonomia das subsidiárias.

Daniel Scumparim d_scumpa@hotmail.com

Analista de Negócios, Pesquisador em Ciências Sociais Aplicadas, Universidade Metodista de Piracicaba - Santa Bárbara D'Oeste - SP, Brasil

Mário Sacomano Neto msacomano@unimep.br

Professor do Programa de Pós Graduação em Administração, Universidade Metodista de Piracicaba - Piracicaba - SP, Brasil

Abstract This study analyzes the characteristics of the Globally Integrated Management Services (GIMS) of a multinational Information Technology and subsidiaries. The study also explores: 1) how the matrix manages resources and deals with the paradox of control and autonomy of the subsidiaries and 2) some differences of the Globally Integrated Management Services (GIMS) the other models of international management: export of services, multinational and transnational. To conduct this research was accompanied GIMS in the deployment of a parent and subsidiary company. The research methodology is qualitative, descriptive and exploratory study, conducted through a case study in parent and subsidiary. Data collection was conducted through interviews with 25 executives of American parent and subsidiary in Brazil. The results show that the adoption of GIMS model generates a relatively utilization of the resources, competencies stimulating local and combines power and control mechanisms of action given matrix with autonomy and independence of the subsidiaries.

keywords Global integrated services management, internationalization models, information technology, subsidiary networks, resources and autonomy in subsidiaries.

Resumen Este estudio analiza las características de la Gestión de Servicios Globalmente Integrada (GSGI) de una multinacional de tecnología de la información y sus subsidiarias. El estudio también explora: 1) cómo la matriz gerencia los recursos y enfrenta la paradoja del control y autonomía de las subsidiarias y 2) algunas diferencias entre la GSGI y otros modelos de gestión internacionales: exportación de servicios, multinacionales y transnacionales. Para realizar la investigación, se realizó el seguimiento de la implantación de la GSGI en la matriz y subsidiaria de una empresa del sector de tecnología de la información. La metodología de la investigación es cualitativa, descriptiva y exploratoria, realizada por medio de un estudio de caso en la matriz y subsidiaria. La recolección de datos se hizo por medio de entrevistas con 25 ejecutivos de la matriz estadounidense y de la subsidiaria brasileña. Los resultados revelan que la adopción de la GSGI genera un relativo aprovechamiento de los recursos, estimulando competencias locales y, todavía, combina mecanismos de control de la matriz con la autonomía e independencia de las subsidiarias.

Palabras clave Gestión de servicios globalmente integrada, modelos de internacionalización, tecnología de la información, redes de subsidiarias, recursos y autonomía de las subsidiarias. 


\section{INTRODUÇÃO}

Ao longo da história da Administração, diversas formas de organizar as operações das empresas em escala global foram utilizadas (BOEHE, 2007; REZENDE e VERSIANI, 2010; MARIN e BELL, 2010; GAMMELGAARD e outros, 2011). Em meados do século XIX, a exportação surgiu como a primeira forma predominante de comércio internacional, com uma empresa organizada em uma matriz e fazendo uso de uma rede de distribuição para entrega dos produtos, normalmente contando com as forças do Estado para proteção dessas operações (CASSANO, 2002). Essa estrutura aplicava-se em diferentes níveis entre países e entre setores produtivos (GUIMARÃES, 1997), baseada em importação de matérias-primas, transformação e exportação de produtos acabados (importação de óleos e exportação de manteiga ou tecido e roupas, por exemplo).

Após a Primeira Guerra Mundial e o colapso das economias nos Estados Unidos e Europa, as corporações internacionais sofreram embargos e bloqueios na comercialização de seus produtos. Em 1920 e 1930, esse protecionismo levou os países a criarem barreiras para entrada de produtos e serviços importados, como elevação nas tarifas, controle monetário e outras. Foi para reduzir incertezas e aproveitar melhor o comércio exterior com subsidiárias atuantes no país destino que surgiu o segundo modelo de gestão internacional, as corporações multinacionais (CHANDLER, 1977). Esse modelo de gestão, fortemente baseado na relação da subsidiária com a matriz, reproduzia cópias da matriz em diferentes locais. O serviço era prestado localmente, com forte dependência em processos e procedimentos oriundos da matriz, e havia pouca, ou nenhuma, flexibilidade na gestão de cada subsidiária.

A expansão da concorrência e o aumento da pressão para elevar a eficiência das corporações, por volta da década de 1980, evidenciaram o esgotamento dos modelos de gestão internacional. Nas multinacionais, as regras eram definidas e ditadas pela matriz e não se aplicavam competitivamente à realidade do país onde determinada subsidiária estava instalada. Essa realidade criou uma crescente interdependência das unidades locais para com a matriz, levando a um terceiro modelo, denominado transnacional (BIRKINSHAW, HOOD, JONSSON, 1998; MAZO, TEIXEIRA, HERNANDES, 2004). A empresa transnacional é construída levando em conta a multinacional operando em múltiplos ambientes, cada um com características próprias, distintas e complexas.
As transnacionais acabaram gerando uma nova deficiência: a tendência à perda de controle da matriz sobre as subsidiárias. Essas últimas poderiam atuar em benefício próprio, com menor contribuição para a organização matriz, conforme explorado por Borini e outros (2009), além de maior dificuldade de compartilhar o conhecimento gerado em cada uma das unidades, devido a esse menor controle. Nesse sentido, Chen e Cannice (2006) apontam duas características específicas para elevar níveis de competitividade das operações globais: (1) atuar de modo independente da matriz para customizar uma solução, produto ou serviço para o mercado local, possibilitando que reduções de custo tornem o serviço mais competitivo contra adversários locais; (2) contar com o conhecimento e recursos da corporação, como um diferencial para com os competidores da mesma região. Então, surgem dois campos de decisão de relativa importância para as operações internacionais: o aproveitamento de recursos e o controle e autonomia das subsidiárias (CHEN e CANNICE, 2006; BORINI e outros, 2009; REZENDE e VERSIANI, 2010).

Com base nessas colocações, algumas questões de pesquisa foram, então, delineadas: Como gerir serviços aproveitando os recursos das subsidiárias? Como a matriz gerencia o paradoxo entre o controle versus a autonomia das subsidiárias na GSGI? Hipoteticamente, quais as diferenças da GSGI para outros modelos de gestão internacional: exportação de serviços, multinacionais e transnacionais? A comparação é hipotética, pois relaciona a GSGI com outros modelos com base na literatura.

Nesse sentido, buscando responder a essas questões, este estudo objetiva analisar as características da GSGI de uma multinacional de tecnologia de informação e subsidiárias. O estudo também explora: 1) como a matriz gerencia os recursos e lida com o paradoxo do controle e autonomia das subsidiárias e 2) algumas diferenças da GSGI dos outros modelos de gestão internacionais: exportação de serviços, multinacionais e transnacionais.

O artigo está estruturado da seguinte forma: apresenta os principais conceitos de internacionalização e modelos de gestão internacional; destaca as diferenças dos modelos de gestão internacional de serviços; apresenta a metodologia, coleta de dados e critérios de análise e, por fim, apresenta os resultados e as análises. Nessa última seção, são apresentadas duas proposições baseadas nos resultados da pesquisa. 


\section{INTERNACIONALIZAÇÃO E MODELOS DE GESTÃO INTERNACIONAL}

Duas abordagens sobre os processos de internacionalização são explorados pela literatura: (1) o modelo de Uppsala de internacionalização da firma (JOHANSON e VAHLNE, 1977), posteriormente reconhecido como modelo relacional de internacionalização (REZENDE e VERSIANI, 2010), e (2) os estudos do desenvolvimento de subsidiárias (BIRKINSHAW, 1994). No modelo relacional, a internacionalização é estudada desde sua evolução por influências externas a diversos elementos até a consolidação de presença internacional via implantação de subsidiária. O modelo relacional explica esse processo pelo conhecimento gerado, acumulado na matriz e transferido para as subsidiárias. Em segunda fase, esse modelo analisa os fluxos e acúmulo de conhecimento entre a subsidiária local e os atores externos, tais quais fornecedores, parceiros e clientes na área de operação da subsidiária, bem como sua transferência para a matriz e entre subsidiárias (REZENDE, 2003)

Os estudos sobre o desenvolvimento de subsidiárias (HONÓRIO, 2009; REZENDE, 2006) focam seus esforços em compreender a evolução da subsidiária tão logo seja implantada em um determinado país (GHOSHAL e BARTLETT, 1990; BIRKINSHAW, 1994; BOEHE, 2007; MARIN e BELL, 2010; GAMMELGAARD e outros, 2011). Os estudos dividem-se em duas subáreas: (1) a rede de relacionamentos intersubsidiária e (2) os mandatos supralocais (REZENDE e VERSIANI, 2010). A primeira subárea trata do relacionamento de uma subsidiária com suas subsidiárias-irmãs, por exemplo, a implantação de controles, de fluxos de informação, de contratos e de infraestrutura, entre outros. A segunda subárea estuda as subsidiárias cujas responsabilidades e atuações vão além de seu país destino, podem ser detentoras de linhas de produtos mundiais com centros de excelência (MOORE e BIRKINSHAW, 1999) ou internacionalizar-se e assumir o controle de outras subsidiárias.

A junção desses dois campos de pesquisa é proposta por estudos recentes, por serem complementares (REZENDE e VERSIANI, 2010). A reflexão sobre esses campos de estudo auxilia na compreensão sobre como as empresas passam de uma operação local à internacionalização e se estabelecem como competidores em escala global, e como as estratégias influenciam esse processo (GRIPSRUD, 1990; JOHANSON e WIEDERSHEIM-PAUL, 1975; STÖTTINGER E SCHLEGELMICH, 1998; KLEIN e ROTH, 1990; MARIN e BELL, 2010). Este estudo sobre a GSGI fornece um modo complementar ao modelo relacional e à literatura de desenvolvimento de subsidiárias, fornecendo mais elementos aos estudiosos para compreender a GSGI como uma forma de gerir as operações em serviços.

\section{Modelos de gestão internacional de serviços: recursos, controle e autonomia}

São vários os estudos que fazem uso dos termos "exportação de serviços", "multinacionais" e "transnacionais" e da gestão de serviço globalmente integrada. Para que possam ser utilizadas dentro do contexto deste trabalho, serão adotadas as seguintes descrições.

\section{Exportação de serviços}

A expressão exportação de serviços pode ser aplicada para qualquer empresa que preste um serviço a distância (PEREIRA, 2002; MAZZOLA, 2005), logo, para este estudo, "exportação de serviços" é entendida como a forma organizacional ligada à ausência de subsidiárias em países diferentes da matriz (ou de não relacionamento entre subsidiária e matriz), com serviço prestado a distância com ou sem movimentação dos profissionais para o local de prestação do serviço (MOROSINI, 2006; PALMISANO, 2006; SCUMPARIM e outros, 2008).

\section{Multinacional}

A expressão MNC ou multinational company é utilizada até hoje para descrever qualquer empresa que possua subsidiárias fora do país de origem (GHOSHAL e BARTLETT, 1990; MONTEIRO, ARVIDSSON, BIRKINSHAW, 2008). Para este estudo, é considerada multinacional a empresa que atuar primariamente com subsidiárias servindo ao mercado local para a qual foram instaladas, tal qual sua descrição clássica (CHANDLER, 1977; PORTER, 1989), sem que as subsidiárias tenham grande autonomia ou exerçam mandatos supralocais (REZENDE e VERSIANI, 2010) e tendo grande dependência da matriz.

\section{Transnacional}

Neste estudo, será utilizada a descrição de transnacional proposta por Birkinshaw, Hood e Jonsson (1998); Moore e Birkinshaw (1999); Mazo, Teixeira e Hernandes (2004), os quais classificam a transnacional como uma empresa cujas subsidiárias detêm maior autono- 
mia para decisões e são mais independentes da matriz, podendo exercer controle sobre outras subsidiárias (mandatos supralocais).

\section{Gestão de Serviço Globalmente Integrada}

Com base na exploração dessas duas características, aproveitamento de recursos e autonomia da subsidiária, opera o quarto modelo de gestão internacional de serviços, a GSGI, objeto desta pesquisa. A GSGI é um modelo de gestão internacional de serviços que aproveita a mão de obra de baixo custo e o capital intelectual onde houver a melhor oferta (SCUMPARIM, 2011). A forte concorrência com as empresas indianas de TI, devido ao baixo custo do profissional indiano comparado com os operários estadunidenses e europeus, exigiu que as grandes corporações ocidentais inovassem na estratégia de gestão das suas operações. Como resultado dessa reorganização, uma empresa de tecnologia de informação, a partir do início do século XXI, e com maior velocidade a partir do ano 2002, passou a adotar e implantar em larga escala um conjunto específico de características, levando à configuração de um novo modelo de gestão internacional, a Globally Integrated Enterprise (GIE), ou Empresa Globalmente Integrada, denominado dessa forma pela própria organização.

Nesse modelo, utiliza-se a infraestrutura de TI para estruturar e operacionalizar o trabalho a distância, não tendo na tecnologia em si o destino final do serviço prestado, facilitando o fluxo de informações e serviços quando comparado a uma empresa industrial tradicional. Certamente o modelo da GSGI levanta questões sobre a autonomia, controle e aproveitamento de recursos das subsidiárias, pois, ao mesmo tempo, emprega controle, autonomia e agrega competências distintas das subsidiárias.

Embora Goshal e Bartlett determinem o termo transnacional como uma evolução das companhias multinacionais (BARTLETT, 1983), nesta pesquisa adotou-se o conceito de transnacional refletindo no papel autônomo de subsidiárias, como explorado por Birkinshaw (1994, 1999). A grande diferença apontada entre uma empresa transnacional e uma multinacional é o paradoxo independência da subsidiária versus controle da matriz. Quanto mais independência tem a subsidiária, mais surge um "efeito colateral", que é a matriz perder muito do controle que possuía sobre as subsidiárias, com algumas delas podendo passar a atuar em benefício próprio, prejudicando ou não contribuindo para os resultados globais da corporação (BIRKINSHAW, 1999; BORINI e outros, 2009). Nesse sentido, o aproveita- mento de recursos e como o paradoxo do controle e da autonomia são controlados são elementos centrais na internacionalização das empresas e, de certa forma, facilitados no modelo da GSGI.

Com base na literatura, alguns critérios foram selecionados para fazer a comparação entre os modelos de gestão de serviços. Os conceitos adotados são detalhados no Quadro 1.

Para o entendimento do aproveitamento de recursos e da forma como a matriz lida com o controle e autonomia das subsidiárias, foram, então, incluídas, com base na literatura, as seguintes categorias de análise: 1) a presença global; 2) a autonomia das subsidiárias; 3) o compartilhamento de serviços e recursos; 4) a integração e compartilhamento de informações; 5) contribuição da subsidiária para a gestão da empresa; 6) a dependência da subsidiária do mercado local; 7) a participação da subsidiária no mercado global; 8) a resiliência e 9) o modelo de entrega dos serviços. Esses critérios, segundo uma ampla revisão de literatura, são centrais para o estudo internacionalização de serviços e das operações globais e a comparação com outros modelos.

\section{METODOLOGIA, COLETA DE DADOS E CRITÉRIOS DE ANÁLISE}

Este estudo de caso pode ser caracterizado como: qualitativo e exploratório, realizado por meio de entrevistas, observação e comparação entre a matriz americana e em uma subsidiária brasileira. Dada a subjetividade do objeto de estudo, a pesquisa qualitativa adequou-se a certas necessidades por envolver um conjunto amplo de informações e um modelo de negócio bastante complexo e inovador. Pela natureza da pesquisa, optou-se por um estudo de caso de cunho fenomenológico, com a criação de proposições teóricas baseadas nos dados, conforme sugerido por Eisenhardt (1989) e Barratt, Choi e Li (2011).

A pesquisa qualitativa permite compreender detalhes das complexas relações entre as subsidiárias, pois a abordagem qualitativa "parte do fundamento de que há uma relação dinâmica entre o mundo real e o sujeito observador [...] O sujeito-observador é parte integrante do processo de conhecimento e interpreta os fenômenos, atribuindo-lhes um significado" (CHIZZOTTI, 1995, p. 79). O estudo é exploratório ao buscar informações sobre um fenômeno e um caso ainda pouco explorado na literatura, com base na observação de uma empresa 


\section{Quadro 1 - Critérios para análise dos modelos de gestão internacional}

\begin{tabular}{|c|c|c|}
\hline Critério & Descrição & Referências \\
\hline 1. Presença internacional: & $\begin{array}{l}\text { Descrição das características de distribuição das subsidiárias ao redor } \\
\text { do globo e nacionalidade }\end{array}$ & $\begin{array}{l}\text { BUCKLEY, GHAURI, } 1999 \text { p. } \\
\text { 37; GUEDES, } 2000\end{array}$ \\
\hline 2. Autonomia das subsidiárias & $\begin{array}{l}\text { Capacidade das subsidiárias de efetuar auto-gestão sem envolvimento } \\
\text { da matriz (controles financeiros, de produção e qualidade por exemplo) }\end{array}$ & $\begin{array}{l}\text { SLANGEN, HENNART, } 2007 \text {, } \\
\text { p. } 6\end{array}$ \\
\hline $\begin{array}{l}\text { 3. Compartilhamento de serviços } \\
\text { e recursos entre as unidades }\end{array}$ & $\begin{array}{l}\text { Grau de compartilhamento de Serviços e Recursos tais como Pesquisa e } \\
\text { Desenvolvimento, Serviços Administrativos, Marketing, RH, entre outros; }\end{array}$ & BIRKINSHAW e outros, 1998 \\
\hline $\begin{array}{l}\text { 4. Integração e } \\
\text { compartilhamento de } \\
\text { informações }\end{array}$ & $\begin{array}{l}\text { Facilidade de acesso à informação e bases de conhecimento entre as } \\
\text { unidades da empresa. Aborda a promoção, coleta, gerenciamento e } \\
\text { distribuição de conhecimento }\end{array}$ & MAHNKE e outros, 2003, p. 1 \\
\hline $\begin{array}{l}\text { 5. Contribuição da subsidiária } \\
\text { para a gestão geral da empresa }\end{array}$ & $\begin{array}{l}\text { Grau de participação das subsidiárias na gestão estratégica e tática da } \\
\text { corporação }\end{array}$ & BIRKINSHAW, 1999 \\
\hline $\begin{array}{l}\text { 6. Dependência da subsidiária } \\
\text { do mercado local }\end{array}$ & $\begin{array}{l}\text { Grau de dependência financeira da subsidiária da renda oriunda de } \\
\text { clientes locais }\end{array}$ & GOMES, 2003, p. 269 \\
\hline $\begin{array}{l}\text { 7. Participação da subsidiária } \\
\text { no mercado global }\end{array}$ & $\begin{array}{l}\text { Grau de renda da subsidiária oriunda de clientes globais (exportação de } \\
\text { serviços) }\end{array}$ & DIAS, GALINA, 2000, p. 5 \\
\hline 8. Resiliência & $\begin{array}{l}\text { Grau de proteção da corporação contra externalidades, tais como guerras, } \\
\text { atentados terroristas, políticas externas, variações cambiais entre outros }\end{array}$ & STARR e outros, 2003, p. 4 \\
\hline 9. Modo de entrega do serviço & $\begin{array}{l}\text { Características de processo de suporte e entrega dos serviços e } \\
\text { composição da carteira de clientes; }\end{array}$ & $\begin{array}{l}\text { HENDERSON e outros, } 2002 ; \\
\text { MCDONOUGH e outros. } 1999\end{array}$ \\
\hline
\end{tabular}

internacional do ramo de serviços em tecnologia da informação (YIN, 1994).

Quanto à qualidade do estudo, buscou-se uma série de cuidados quanto à validade de constructo e de confiabilidade sugeridos por Yin (1994). Buscou-se, quanto à validade de constructo, criar categorias iniciais com base na literatura e utilizar múltiplas fontes de evidência sobre os modelos. Quanto à confiabilidade, utilizaram-se os protocolos e uma espécie de banco de dados com as informações.

\section{Coleta e análise dos dados}

A coleta de dados envolveu um amplo conjunto de informações por meio de entrevistas in loco. As entrevistas, quando permitido, foram gravadas e tiveram como eixo um roteiro de entrevistas semiestruturado. As entrevistas e observação participante foram executadas em duas fases, descritas a seguir.

A primeira fase envolveu entrevistas com 25 gestores e executivos das seguintes áreas da empresa: Gerentes de Projetos Internacionais, Gerentes de Entrega de Serviço, Executivo de Entrega de Projeto, Gerente
Geral de Subsidiária, Executivo de Suporte a Sistemas Operacionais, Executivo de Contato e Relacionamento, localizados principalmente na subsidiária brasileira (20 pessoas) e também na matriz americana ( 5 pessoas). Essas entrevistas foram feitas pessoalmente, tanto as da subsidiária brasileira quanto as da matriz nos Estados Unidos. A relação das entrevistas executadas é apresentada no Quadro 2.

A segunda etapa da coleta foi composta por participação em fóruns e discussões acerca do modelo de gestão global de serviços, promovidas pela própria empresa, além de uma análise de documentos e observação participante realizada durante cinco meses, efetuada dentro da subsidiária brasileira e de uma unidade da empresa nos Estados Unidos. Nos fóruns, as discussões, análise de relatórios e documentos permitiram a compreensão dos papéis das demais subsidiárias para a gestão global.

A técnica de análise dos dados envolveu a avaliação de conteúdo e o procedimento analítico geral, na qual as notas de campo são registradas e transformadas em categorias de análise, conforme explicam Collins e Hussey (2005). A comparação dos modelos de gestão 


\section{Quadro 2 - Entrevistas realizadas}

\begin{tabular}{|c|c|c|c|c|}
\hline Cargo do entrevistado & Pais & $\begin{array}{l}\text { Data da } \\
\text { entrevista }\end{array}$ & $\begin{array}{c}\text { Duração da } \\
\text { entrevista (min) }\end{array}$ & Roteiro de entrevista \\
\hline Executivo de entrega de projeto & EUA & 14-mai-07 & 25 & \multirow{11}{*}{$\begin{array}{l}\text { - Explicar brevemente os } \\
\text { objetivos da entrevista e } 0 \\
\text { conceito adotado para GSGI } \\
\text { 1. Quando a sua geografia } \\
\text { começou a operar no modelo } \\
\text { de GSGI? }\end{array}$} \\
\hline Executivo de entrega de projeto & EUA & 17-mai-07 & 90 & \\
\hline Executivo de suporte à sistemas operacionais & EUA & 17-mai-07 & 30 & \\
\hline Gerentes de projetos internacionais & EUA & 16-mai-07 & 60 & \\
\hline Service delivery managers & EUA & 17-mai-07 & 60 & \\
\hline Executivo de contato e relacionamento & Brasil & 15-jun-07 & 60 & \\
\hline Executivo de entrega de projeto & Brasil & 9 -abr-07 & 90 & \\
\hline Executivo de entrega de projeto & Brasil & $11-a b r-07$ & 30 & \\
\hline Executivo de entrega de projeto & Brasil & 29-jun-07 & 60 & \\
\hline Executivo de entrega de projeto & Brasil & $12-a b r-07$ & 30 & \\
\hline Executivo de entrega de projeto & Brasil & 12-abr-07 & 60 & \\
\hline Executivo de entrega de projeto & Brasil & $12-a b r-07$ & 60 & \multirow{3}{*}{$\begin{array}{l}\text { 2. Quais fatores contribuiram } \\
\text { para a adoção deste modelo } \\
\text { de gerenciamento? }\end{array}$} \\
\hline Executivo de suporte à sistemas operacionais & Brasil & $9-a b r-07$ & 60 & \\
\hline Gerente geral de subsidiária & Brasil & 14-jun-07 & 90 & \\
\hline Gerentes de projetos internacionais & Brasil & $10-a b r-07$ & 60 & \multirow{2}{*}{$\begin{array}{l}\text { 3. Como a GSGl opera? Qual } \\
\text { é o fluxo de trabalho? }\end{array}$} \\
\hline Gerentes de projetos internacionais & Brasil & $11-a b r-07$ & 60 & \\
\hline Gerentes de projetos internacionais & Brasil & $13-a b r-07$ & 60 & \multirow{9}{*}{$\begin{array}{l}\text { 4. Quais são os principais } \\
\text { benefícios e desafios na } \\
\text { GSGI? }\end{array}$} \\
\hline Gerentes de projetos internacionais & Brasil & 6-jul-07 & 60 & \\
\hline Gerentes de projetos internacionais & Brasil & $13-a b r-07$ & 30 & \\
\hline Service delivery managers & Brasil & $10-a b r-07$ & 60 & \\
\hline Service delivery managers & Brasil & $16-a b r-07$ & 60 & \\
\hline Service delivery managers & Brasil & 7-mai-07 & 30 & \\
\hline Service delivery managers & Brasil & $16-a b r-07$ & 60 & \\
\hline Service delivery managers & Brasil & $17-a b r-07$ & 60 & \\
\hline Service delivery managers & Brasil & 17-abr-07 & 30 & \\
\hline
\end{tabular}

internacional de serviços por meio dessa técnica permitiu uma melhor comparação e entendimento das diferenças que as tornam singulares e distintas dos modelos de gestão internacional. Também algumas proposições foram lançadas com base no caso, conforme sugerido por Eisenhardt (1989) e Barratt, Choi e Li (2011).

\section{RESULTADOS DA PESQUISA}

A empresa pesquisada atua no segmento de tecnologia da informação e serviços de apoio aos negócios, operando em cinco principais áreas: (1) serviços de apoio aos negócios, (2) desenvolvimento de software, (3) desenvolvimento de hardware, (4) serviços de TI e (5) serviços financeiros.

A empresa tem mais de 350 mil funcionários, divididos em regiões definidas como Américas, Ásia-Pacífico e Europa-África. A empresa mantém negócios em 87 países e as maiores e mais significativas subsidiárias são localizadas: a matriz, nos Estados Unidos, além de no Brasil, Índia, Japão, Alemanha, Inglaterra, França, Austrália e Argentina, sendo que, em relação às áreas de serviços globais, podemos citar como chave Argentina, Brasil e Índia. 


\section{Centros de prestação de serviços, ferramentas, estrutura e gestão de operações globais}

A empresa de serviços globalmente integrada tem como pilar de sustentação a criação de unidades ou Centros de Prestação de Serviços. No modelo da GSGI, buscou-se criar centros de excelência em prestação de serviços em localidades estratégicas, aproveitando as melhores condições de custo, como: níveis salariais, diferenças cambiais e incentivos das várias subsidiárias. A empresa possui esses centros em países-chave, como Brasil, Rússia, Índia, China, Argentina e Leste Europeu.

As ferramentas globais compreendem os recursos de TI, como infraestrutura de redes, de comunicações e telefonia, sistemas operacionais, compartilhamento de telas, ferramentas de colaboração, correio eletrônico, comunicação instantânea, videoconferência e aplicativos de suporte aos negócios, que, se bem explorados, permitem a colaboração remota e entrega do serviço prestado a partir de um dos centros de delivery, como processamento de contratos, suporte a sistemas operacionais de servidores ou mesmo gerenciamento de equipes e projetos.

A estrutura das operações compreende o eixo central para prover autonomia e possibilitar iniciativas das subsidiárias que levem à inovação, mas sem perder a força que mantém os negócios alinhados com a matriz ao redor do globo; a empresa na GSGI organiza as suas operações em uma matriz tridimensional: 1) Negócios, 2) Geografias e 3) Funções. A primeira dimensão, centrada em unidades de negócio completas, funciona melhor quando as linhas de negócios são distintas, compartilham poucas operações comuns e vendem para clientes diferentes, como cinco áreas em que a empresa estudada atua: serviços de tecnologia e de apoio aos negócios, manufatura, financiamento, desenvolvimento de software. A segunda dimensão geográfica pode ser atrelada a uma subsidiária com foco regional, clientes e fornecedores nacionais ou locais. A terceira dimensão das funções pode ser entendida como um híbrido dos dois: unidades de negócios (como P\&D) e por geografia (como marketing e vendas). Esses elementos constituem a estrutura da GSGI.

Para garantir que essas três dimensões de operações funcionem, a GSGI deve contar com um sistema avançado de gestão global por meio de experientes gestores atuando em funções específicas, como descrito a seguir, envolvendo:

- $\quad$ O Gerente de Negócios (Estrategista + Arquiteto + Coordenador): os gerentes de negócios, ou gerentes de divisão de serviços, têm uma responsabili- dade de aumentar a eficiência e competitividade da companhia em escala global.

- O Gerente do País (Sensor + Construtor + Contribuidor): para a gerência de geografias da empresa analisada, esse administrador é quem cuida de uma subsidiária nacional.

- O Gerente Funcional (Scanner + Integrador + Campeão): os gerentes funcionais garantem que as linhas de serviço estejam integradas entre as geografias (ou centros de prestação de serviço).

- A gestão de um time de entrega é de responsabilidade da subsidiária onde está localizado e, para manter o controle que a matriz pode exercer, mas sem tirar a flexibilidade nas operações, os diferentes tipos de serviço prestado (como os exemplos acima) são quebrados em linhas de serviço. Quanto mais específica for a linha de serviço (como suporte a servidores Windows em Plataforma Intel), mais fácil é para a matriz criar medidores de performance e qualidade que deixem claro qual dos centros de serviço está atuando de modo mais competitivo no momento. Logo, os novos (e atuais) contratos podem ser redirecionados para aquele ou outro centro de serviço, aproveitando a melhor situação e aumentando a rentabilidade.

\section{Exploração de recursos das subsidiárias}

Durante os estudos e observações, notou-se que esse modelo de gestão permite uma flexibilidade muito grande na gestão dos recursos da subsidiária. A análise de possibilidades de exploração será feita em três áreas: recursos financeiros, pessoas e conhecimento.

A empresa pesquisada possui atuação em mais de 100 países, mas nem todas as subsidiárias atuam em GSGI. A matriz americana, japonesa e as subsidiárias europeias em geral assumem o papel de vendedoras de serviços, devido ao custo comparativamente maior dos seus profissionais. Assim sendo, essas subsidiárias "leiloam" os serviços para as demais subsidiárias, chamadas de "centros de prestação de serviços globais", localizadas no Brasil, Argentina, Índia, Rússia, China e Leste Europeu, sendo os centros mais significativos Brasil, Argentina e Índia, pois possuem mais de 80\% do quadro de pessoas da empresa que atuam em GSGI.

\section{Recursos financeiros}

As subsidiárias têm autonomia para decidir investimentos e onde aplicar os recursos recebidos pela corpora- 
ção. No caso da subsidiária brasileira, esses planos de expansão no mercado, parcerias com universidades, acordos governamentais, entre outros, são definidos e criados pela subsidiária e apenas comunicados à matriz, ou é solicitada verba de investimento, como nos casos de ampliação predial. Cada subsidiária tem também graus de investimento diferentes, logo planos de expansão que requeiram grandes investimentos podem ser negados pela matriz, se houver, por exemplo, melhores incentivos em outra região.

\section{Pessoas}

A subsidiária brasileira possui o corpo de funcionários dividido em duas grandes áreas: o time comercial e o time GSGI. As pessoas que atuam no time comercial prestam serviços aos clientes cujo contrato é feito diretamente com a subsidiária brasileira, onde o lucro oriundo dessas operações é gerido pela subsidiária. O time GSGI é o grupo de pessoas que prestam serviços globalmente, recebendo os contratos, por exemplo, da matriz estadunidense. Essa divisão traz benefícios tanto para a subsidiária quanto para a corporação. Nas operações comerciais da subsidiária brasileira, onde os contratos e o lucro pertencem à subsidiária, a forma de operação, cultura e especificidades do trabalho acompanham o ritmo das empresas brasileiras, contando com profissionais que não necessitam conhecimento de língua estrangeira, enquanto nas operações GSGI a própria forma de atuação e cultura do país atendido requerem atenção à parte para o bom andamento do trabalho e relações comerciais.

\section{Conhecimento}

Apesar de as pessoas estarem divididas entre operações comerciais e GSGI, há muita sinergia entre os times. Avanços da corporação na gestão de performance, ferramentas de trabalho e métodos são rapidamente analisados e incorporados nas atuações do time comercial, e inovações e boas práticas do time comercial também são compartilhadas para o time GSGI e com a corporação como um todo, por meio de um dos vários canais existentes na empresa para análise de sugestões e projetos de iniciativa dos funcionários. Essas características permitem à corporação escolher e explorar o potencial de recursos de uma ou de outra subsidiária na gestão de contratos globais, não apenas do ponto de vista de custo dos profissionais. Assim, vários fatores podem influenciar na decisão da empresa de enviar um contrato global para um ou outro centro de prestação de serviço, como: custo; afinidade cultural do cliente; demandas específicas do cliente final; oferta de proficiência; fuso horário; ociosidade, entre outros.

\section{Mecanismos de controle e autonomia}

Na GSGI, as subsidiárias possuem uma grande independência para decidir o papel que devem desempenhar, a forma de gerir e capacitar pessoas, investimentos e gestão comercial em geral, mas alguns mecanismos foram criados para possibilitar à matriz manter um certo grau de controle e evitar que a subsidiária atue apenas em benefício próprio, podendo ser divididos em: (a) mecanismos de controle fiscal e de segurança, (b) controle de conhecimento, (c) controle de adequação a boas práticas e (d) controle de performance, sendo esses dois últimos os mais dinâmicos na GSGI.

\section{Mecanismos de controle fiscal e de segurança}

Os mecanismos de controle fiscal não diferem do comumente encontrado em grandes empresas multinacionais, pois todas têm que atender a normas e leis, à revelia do fato de que, como os recursos que prestam serviços para uma subsidiária podem estar situados em outro país, uma auditoria financeira que acontece em um país pode ter que se estender a uma ou outra subsidiária que esteja prestando serviços. Além dos controles externos, a matriz possui uma estrutura de controle fiscal única e global, o que permite comparar resultados periodicamente entre todas as subsidiárias, avaliar desempenho por cada um dos segmentos de negócios em que atua e definir, ou cobrar definição, de planos para retomar as metas. No início do ano, são definidas metas de crescimento e de lucratividade entre cada subsidiária e a matriz, e esses resultados são acompanhados durante o ano. Assim, a matriz mantém um controle dos lucros esperados e a subsidiária tem uma certa liberdade para atuar durante o ano, desde que focando nas metas definidas por ela e fechadas com a matriz e sendo acompanhada em inúmeras auditorias internas e externas.

\section{Mecanismos de controle de conhecimento}

São definidos times específicos para zelar e desenvolver a gestão de conhecimento em escala global, sendo papel desses times definir estratégias de gestão de conhecimento para toda a corporação, promover ferramen- 
tas e bancos de dados, criar iniciativas de propaganda interna para conscientizar as pessoas a fazerem uso dos sistemas de registro de ideias. Esses times contam com outros grupos nas subsidiárias responsáveis pela implementação das políticas definidas globalmente pela matriz. Dessa forma, toda a corporação conta com repositórios padronizados para consultas, podendo a matriz acessar e compartilhar entre subsidiárias o conhecimento acumulado. Quanto ao conhecimento tácito, a gestão de pessoas considera o registro de talentos e de recursos críticos, que são as pessoas dificilmente substituíveis e de conhecimento raro.

\section{Mecanismos de controle adequação a boas prăticas}

A GSGI funciona dentro de um framework de trabalho baseado em melhores práticas de mercado, como Information Technology Infrastructure Library (ITIL), Project Management Body of Knowledge (PMBOK), International Organization for Standardization (ISO), Manufatura Enxuta (Lean) e Sei Sigma (Six Sigma), e alguns padrões criados pela própria corporação. A adoção e uso desses padrões definidos por todas as subsidiárias, seja na parte delas que atue com o mercado local ou na parte que atue prestando serviços para outras subsidiárias, é fortemente controlada pela matriz, via auditorias constantes e programas de conscientização. Os resultados dessas auditorias para verificar se cada subsidiária está alinhada com as melhores práticas definidas pela matriz são compartilhados com todas, e um programa de reconhecimento é instituído para premiar as pessoas que sejam destaque no uso desse framework.

\section{Mecanismos de controle de performance}

Para que a matriz possa controlar a performance de serviços das subsidiárias, a ferramenta utilizada é a adoção de medidores padronizados de performance de qualidade e produtividade entre todas as subsidiárias. Para que isso possa ser feito, é vital que os times estejam divididos em linhas de serviços que prestem o mesmo escopo de trabalho, como suporte a servidores Windows em Plataforma Intel. Uma vez que os times dos centros de prestação de serviços estejam atuando em escopos semelhantes, são definidos medidores padrões de qualidade e produtividade, por exemplo: (1) quantidade de servidores suportados por funcionário, (2) percentual de chamados fechados dentro do prazo, (3) quantidade de reclamações recebidas, entre outros. Uma vez implementados esses padrões, a matriz pode contar com medidores e auditorias para comparar cada uma das subsidiárias e, com essa clareza, torna-se possível identificar as subsidiárias que têm a maior produtividade e transferir melhores práticas entre elas. E a subsidiária, por sua vez, tem a autonomia para receber e decidir investimentos, ampliação de mercado e gestão em geral, desde que adote os mecanismos padronizados pela corporação. Como as metas não são definidas unilateralmente, mas, sim, com uma discussão e acordo entre matriz e cada uma das filiais, pôde ser observado esse balanço entre o controle da matriz versus autonomia das subsidiárias.

\section{Diferenças entre os modelos de internacionalização}

Depois de analisar as características da GSGI, notam-se as diferenças desse modelo da multinacional clássica e das transnacionais em vários aspectos, principalmente por formar centros de prestação de serviços em locais estratégicos e aproveitar o potencial desses centros para entregar o serviço em outras partes do mundo. O trabalho também pode ser trocado de centro em centro a curto prazo (algo entre dias ou poucas semanas, dependendo das necessidades), para aproveitar as melhores condições, como oferta de profissionais específicos ou variações cambiais. A GSGI também constitui uma excelente proteção contra fatores externos e incertezas, uma vez que o centro que presta serviço a um cliente específico pode ser mudado com bastante agilidade para outro país.

O Quadro 3 apresenta uma comparação entre os modelos de gestão internacional, com a adição da GSGI, para tornar mais claro o entendimento das diferenças entre eles, sendo uma compilação da bibliografia pesquisada e do estudo de caso.

Com base nessa tabela, comparando os diferentes modelos de gestão internacional de serviços, alguns pontos merecem destaque, como a similaridade entre a GSGI e a exportação de serviços nos itens de presença internacional e modo de entrega de serviço. A diferença é que a exportação de serviços conta apenas com a matriz e mão de obra presente no mesmo país, enquanto a GSGI conta com os centros de prestação de serviços e a sinergia entre eles para vender serviços globais.

Outro ponto de destaque da GSGI, agora em relação à multinacional e transnacional, é a independência de suas subsidiárias do seu mercado local, como visto nos itens "Dependência da subsidiária do mercado local" e "Participação da subsidiária no mercado global". Esses pontos destacam o papel das subsidiárias da 


\section{Quadro 3 - A GSGI e os modelos de gestão internacional de serviços}

\begin{tabular}{|l|}
\hline Característica \\
\hline $\begin{array}{l}\text { Presença } \\
\text { internacional }\end{array}$ \\
Autonomia das \\
subsidiárias
\end{tabular}

Distribuição de investimentos

\section{Contribuição da subsidiária para a gestão geral da empresa}

Dependência da subsidiária do mercado local

Participação da
subsidiária no
mercado global

\section{Resiliência}

Modo de entrega do serviço

Modo de gestão de pessoas

\section{Exportação de serviços}

Majoritariamente escritórios de representação

Não se aplica

Apenas de mercado

Não Há

Não se aplica subsidiária têm como final servir os clientes daquela localidade

Apenas de mercado e da matriz para com a subsidiária

\section{Majoritariamente só} o necessário para operação e expansão da subsidiária no mercado local

Fraca, uma vez que as iniciativas não são plenamente incentivadas

\section{Alta, já que a}

Baixa (apenas alguns serviços específicos)

Baixa

Desenvolvido na subsidiária e entregue ao cliente local

entregue aos clientes globais

Hierarquia vertical

\section{Transnacional}

GSGI

Majoritariamente plantas de suporte e entrega de serviços para mercado local

Alto (a subsidiária fica livre para tomar decisões estratégicas, com pequena intervenção da matriz)

Médio (se a matriz souber explorar e fomentar as iniciativas das subsidiárias)

Relativo à habilidade da matriz para padronizar e incentivar uso de base de conhecimento

Majoritariamente só o necessário para operação e expansão da subsidiária no mercado local, com financiamento de iniciativas

Forte, uma vez que as iniciativas são incentivadas, mas pode ficar restrito apenas ao país se a matriz não souber explorar

Alta, já que a subsidiária têm como final servir os clientes daquela localidade

Baixa (apenas alguns serviços específicos)

Baixa

Desenvolvido na subsidiária e entregue ao cliente local

Hierarquia vertical entre a matriz e subsidiárias. Pode haver estrutura matricial em rede dentro da subsidiária
Intenso, com políticas claras entre todas as unidades

Depende de análise e planos globais, uma vez que a subsidiária fornece serviços para os clientes globais (pouca relação com 0 desempenho no mercado local)

Forte, uma vez que o controle é dividido com as subsidiárias, e uma delas pode ser a detentora de uma linha de serviço global

Variável, uma vez que a subsidiária provê serviços para outras unidades e para clientes globais

Alta (os clientes são globais)

Alta (a entrega à um cliente pode realizada em um centro de serviço de outro país)

Desenvolvido no centro de prestação de serviço e entregue aos clientes globais

Predominantemente matricial em rede, inclusive entre as unidades e matriz 
GSGI, que atuam como centro de prestação de serviços, como exportadores, assumindo parte ou totalmente a responsabilidade pela prestação de serviços de um contrato fechado entre outra subsidiária da empresa pesquisada e o cliente final.

Alguns itens também relatam as diferenças da GSGI, como "Resiliência", na "Contribuição da subsidiária para a gestão geral da empresa", no "Compartilhamento de serviços e recursos entre as unidades", onde a GSGI parece diferir das demais. A questão de "Compartilhamento de serviços e recursos entre as unidades" é interessante, pois destaca a diferença entre multinacional e transnacional, ficando a multinacional no papel de seguidora dos processos e procedimentos da matriz. Por fim, a "Autonomia das subsidiárias" relata a subserviência da subsidiária para com a matriz na multinacional, a sua alta independência na transnacional e, na GSGI, a busca pelo balanço no paradoxo controle da matriz $\mathrm{X}$ autonomia da subsidiária. Esses elementos denotam diferenças bem interessantes da GSGI para as outras formas de internacionalização de serviços.

\section{ANÁLISE DOS RESULTADOS}

Na empresa foco do estudo, a GSGI tem se mostrado eficiente para aproveitar recursos, conseguindo agregar valor ao serviço, tirando proveito das vantagens locais onde estão situados os seus centros de prestação de serviços. Apesar de a GSGI conter mecanismos de comando em centros de excelência ou em organização operacional (FROST, BIRKINSHAW, ENSIGN, 2002; MOORE e BIRKINSHAW, 1999; SINHA, 2005) que podem ser encontrados em outros modelos de gestão internacional de serviços, os resultados da pesquisa indicam a diferença da GSGI para os demais modelos de gestão de serviços, principalmente no papel desempenhado pelas subsidiárias, na sua concorrência interna por contratos globais, e demais características relativas a autonomia e controle.

Em nenhum material estudado, notou-se uma forma de atuação, em serviços, semelhante à observada na empresa estudada, seja na multinacional clássica de Chandler (1977) ou mesmo na literatura de desenvolvimento de subsidiárias que, conforme Moore e Birkinshaw (1998) e Mazo (2004), apesar de relacionar os mandatos supralocais e papéis mais ativos das subsidiárias, não relata um repositório de recursos tão flexível como observado por GHOSHAL e BARTLETT (1990); a decisão pela centralização ou descentralização deve basear-se em tarefas.
Outro resultado da pesquisa indica que a GSGI configura-se em uma forma distinta para buscar autonomia da subsidiária mantendo o controle da matriz nas áreas-chave, uma vez que as subsidiárias têm autonomia de investimentos e crescimento (mesmo que o mercado local daquela subsidiária não esteja crescendo), ficando a matriz com o controle em alguns itens que permeiam toda a rede de subsidiárias, divididas em linhas de serviço padronizadas ao redor do globo, com medidores que acompanham a eficiência entre as unidades, podendo adotar melhores práticas e replicar em toda a rede.

Dentro desse paradoxo controle da matriz versus autonomia da subsidiária, o papel desempenhado pela matriz foi o de definir padrões globais e assegurar que sejam seguidos, pois assim ela pode comparar os resultados e o que acontece entre as subsidiárias, facilitando a tomada de decisão e atuação em áreas com problemas. Também fica a matriz responsável pela definição de metas em conjunto com as subsidiárias, sendo esta uma atividade significativa, pois é nela que a subsidiária pode assumir riscos (e solicitar investimentos) para metas de crescimento mais agressivas ou pelo conhecimento maior do mercado do que a matriz. Uma vez que a matriz tenha concordado com a meta definida pela subsidiária, esta tem autonomia para tomada de decisão, mas, mesmo assim, a matriz consegue ter o controle dos resultados, por meio de medidores periódicos de performance. Essa construção e balanço entre autonomia da subsidiária e controle da matriz permite uma relação harmônica entre os executivos e grupos de trabalho. Nesse sentido, conforme sugerem Eisenhardt (1989) e Barratt, Choi e Li (2011), formularam-se proposições teóricas com base nos dados no sentido de delinear futuros estudos sobre o tema. Conforme exploram alguns estudos (BIRKINSHAW, 1999; BORINI e outros, 2009) formulou-se a primeira proposição da pesquisa:

Proposição 1: A GSGI combina mecanismos de controle, mas estimula a autonomia e a formação de competências locais nas subsidiárias.

A sua forma de gerir recursos globalmente é especialmente desenhada para segmentar o trabalho, redirecionando para os centros de prestação de serviços as "fatias" do trabalho que possam ser executadas remotamente, aproveitando, dessa forma, os melhores talentos e custos de cada subsidiária e fazendo uma gestão de pessoas como se as subsidiárias fossem uma unidade, conforme o modelo relacional de internacionalização ou de redes apresentado por Rezende e Versiani (2010). 
Essa forma de gestão gera ganhos de eficiência, além de resiliência, tornando-se bastante competitiva, conforme resultados já percebidos pelos clientes. Nesse contexto de exploração de recursos das subsidiárias, os contratos são geridos globalmente, podendo um país "terceirizar internamente" parte do trabalho para outro centro de serviço. Essa movimentação é feita não focando apenas o acesso a profissionais de menor custo (característicos de cada país), mas também o acesso a talentos distintos e que possam ser raros no país de origem daquele contrato. Assim sendo, a GSGI conta com os melhores aspectos das suas subsidiárias para gerir os contratos e dividir os serviços entre um ou outro centro, conforme exploram alguns estudos (GHOSHAL e BARTLETT, 1990; BIRKINSHAW, 1994; BOEHE, 2007; MARIN e BELL, 2010; GAMMELGAARD e outros, 2011). Dessa maneira, formulou-se a segunda proposição da pesquisa:

Proposição 2: A GSGI promove um significativo aproveitamento dos recursos, pessoas e conhecimento entre as subsidiárias.

Dentro da literatura explorada, percebe-se que, para a indústria de fabricação de bens, esse tipo de fabricação segmentada globalmente tem se tornado comum, mas, para serviços, nenhum relato ou conhecimento compilado foi encontrado, sendo observado apenas na empresa estudada, conforme SSME (2008), Paulson (2006) e Gereffi (2007).

Enviar o serviço aonde possa ser feito melhor, e mais barato, tem sido a busca de muitas empresas, com a abertura de mercado. Se, para empresas de manufatura, a montagem de uma planta em outro país, como a China, por exemplo, é uma decisão estratégica e de longo prazo (algumas empresas levam anos para começar a operar), para os serviços, que podem ser prestados remotamente, a GSGI configura uma rentável melhor prática para dar o dinamismo e controle necessários ao melhor proveito dos recursos e da situação de uma subsidiaria que contenha um centro de prestação de serviço, além de apresentar uma boa proteção contra eventos externos que possam interromper a prestação do serviço ao cliente final.

\section{CONSIDERAÇÕES FINAIS}

Ao perseguir o objetivo de analisar as diferenças entre a GSGI e a exportação de serviços, multinacionais e transnacionais, tradicionalmente presentes no corpo de conhecimento da administração, buscou-se encontrar em campo um modelo de gestão distinto dos outros modelos de internacionalização de serviços. O levantamento bibliográfico e comparações qualitativas culminaram em uma relação de fatores que as diferenciam em aspectos particulares, relacionando também áreas que são comuns, com explicações que foram generalizadas em tabela comparativa.

Dentro dos objetivos secundários deste trabalho, o texto foi caracterizando e explorando o funcionamento da GSGI e dos demais modelos de gestão internacional de serviços. A GSGI configurou-se como uma importante alternativa para a gestão de serviços, contando com uma inovadora forma de aproveitamento de recursos das subsidiárias, balanceando, mediante diversos mecanismos de controles, o paradoxo de controle da matriz versus autonomia das subsidiárias.

O modelo de GSGI apresenta elevado nível de combinação de mecanismos de controle, mas estimula a autonomia e a formação de competências para mandatos supralocais. O modelo também promove um significativo aproveitamento dos recursos, pessoas e conhecimento entre as subsidiárias, conforme explorado na literatura sobre internacionalização de subsidiárias (BIRKINSHAW, 1999; BORINI e outros, 2009; GHOSHAL E BARTLETT, 1990; BIRKINSHAW, 1994; BOEHE, 2007; MARIN e BELL, 2010; GAMMELGAARD e outros, 2011).

Não obstante, existem limitações neste estudo quanto a sua pretensão de comprovar as diferenças da GSGI, posicionando-a em definitivo como um modelo de gestão internacional de serviços. A principal limitação é o fato de ser um estudo de caso, não contando com pesquisa e comparações com outras organizações de outros tipos e setores. Outros pontos de atenção incluem as limitações típicas do paradigma de pesquisa qualitativo que teve que ser adotado neste primeiro estudo, impossibilitando a criação de uma estrutura teórica dedutiva que levasse a hipóteses e seus testes.

Sendo esta pesquisa o início da compreensão da GSGI como uma forma distinta de gestão internacional de serviços, diversos estudos futuros podem ser propostos, tais quais: (a) estudos sobre a densidade e relações de redes intraorganizacionais dentro da gestão de serviços globalmente integrada; (b) estudos sobre a geração de capacidade e recursos relacionais no desenvolvimento de subsidiárias; (c) estudos comparativos de grandes empresas de serviços e sua caracterização dentro de um dos modelos internacionais de gestão de serviços; (d) estudos subjetivos visando compreender a questão da cultura na adoção de um modelo tão glo- 
balmente integrado; (e) estudos em profundidade sobre os mecanismos de controle da matriz e suas influências na autonomia das subsidiárias; (f) estudos quantitativos sobre equações e sistemas para cálculo de risco e distribuição de atividades e contratos globais entre os centros de prestação de serviços.

O estudo contribui, do ponto de vista teórico, com o levantamento de possibilidades de gestão não exploradas nos estudos de internacionalização que vão além dos mandatos supralocais das subsidiárias, pois o pouco material desenvolvido para compreender serviços não relata um modelo similar ao da GSGI para gerir recursos das subsidiárias. Do ponto de vista prático, o estudo relaciona os principais aspectos adotados para a administração de serviços nesse modelo de gestão, tais quais criação de centros de prestação de serviços, padronização global de ferramentas e organização operacional, gestão financeira e de pessoal e dos mecanismos de controle de subsidiárias. Distante de encerrar o tema, diante da elevada internacionalização das empresas, novos estudos são necessários no sentido de entender a forma de gestão, sinergias intraorganizacionais e seus impactos no controle e autonomia das subsidiárias.

\section{REFERÊNCIAS}

BARRATT, M; CHOI, T. Y; LI, M. Qualitative case studies in operations management: trends, research outcomes, and future research implications. Journal of Operations Management, v. 29, n. 4, p. 329-342, 2011.

BARTLETT, C. A. MNCs: get off the reorganization merry-go-round. Harvard Business Review, v. 26, n. 2, p. 138-146, 1983.

BIRKINSHAW, J. Approaching heterarchy: a review of the literature on multinational strategy and structure. Advances in International Comparative Management, v. 9, p. 111- 144, 1994.

BIRKINSHAW, J. The determinants and consequences of subsidiary initiative in multinational corporations. Entrepreneurship: Theory and Practice, n. 24, 1999.

BIRKINSHAW, J; GHAURI, P. N. The internationalization of the firm. Cengage Learning EMEA, 1999. p. 37.

BIRKINSHAW, J; HOOD, N; JONSSON, S. Building firm-specific advantages in multinational corporations: the role of subsidiary initiative. Strategic Management Journal, v. 19, n. 3, p. 221-241, 1998.
BOEHE, D. M. Desenvolvimento de produtos em subsidiárias de empresas multinacionais no Brasil. RAE-Revista de Administração de Empresas, v. 47, n. 1, p. 32-45, 2007.

BORINI, F. M. e outros. A relevância das iniciativas de subsidiárias para as multinacionais brasileiras. RAE-Revista de Administração de Empresas, v. 49, n. 3, p. 253-265, 2009.

CASSANO, F. A. A teoria econômica e o comércio internacional. Pesquisa \& Debate, v. 13, n. 1, p. 112-128, 2002.

CHANDLER, A. D. The visible hand: the managerial revolution in American business. Cambridge: Harvard University Press, 1977.

CHEN, R; CANNICE, M. V. Global integration and the performance of multinational's subsidiaries in emerging markets. Ivey Business Journal. v. 70, n. 3, p. 1-9. 2006.

CHIZZOTTI, A. Pesquisa em ciências humanas e sociais. 2. ed. São Paulo: Cortez, 1995.

COLlins, J.; HUSSEY, R. Pesquisa em Administração. Porto Alegre: Bookman, 2005.

EISENHARDT, K. M. Building theories from case study research: academy of management. The Academy of Management Review, v. 14, n. 4, p. 532, 1989.

FROST, T. S; BIRKINSHAW, J. M; ENSIGN, P. C. Centers of excellence in multinational. Strategic Management Journal, v. 23, n. 11, p. 997-1018, 2002.

GAMMELGAARD, J. e outros. Effective autonomy, organisational relationships and skilled jobs in subsidiaries. Management Research Review, v. 34, n. 4, p. 366-385, 2011.

GEREFFI, G. Promessa e desafios do desenvolvimento. Tempo Social USP, v. 19, n. 1, p. 223-248, 2007.

GHOSHAL, S; BARTLETT, C. A. The multinational corporation as an interorganizational network. Academy of Management Review, v. 15, n. 4, p. 603-625, 1990.

GRIPSRUD, G. The determinants of export decisions and attitudes to a distant market: Norwegian fishery exports to Japan. Journal of International Business Studies, v. 21, n. 3, p. 469-485, 1990.

GUIMARÃES, E. P. Evolução das teorias de comércio internacional. Estudos em Comércio Exterior, v. 1, n. 2, p. 1-19, 1997. 
HONÓRIO, L. C. Determinantes organizacionais e estratégicos do grau de internacionalização de empresas brasileiras. RAE-Revista de Administração de Empresas, v. 49. n. 2, p. 162-177, 2009.

JOHANSON, J; VAHLNE, J. E. The internationalization process of the firm: a model of knowledge development and increasing foreign markets commitments. Journal of International Business Studies, p. 23-32, 1977.

JOHANSON, J; WIEDERSHEIM-PAUL, F. The internationalization of the firm: four Swedish cases. The Journal of Management Studies, v. 12, n. 3, p. 305-322, 1975.

KLEIN, S; ROTH, V. J. Determinants of export channel structure: the effects of experience and psychic distance reconsidered. International Marketing Review, v. 7, n. 5, p. 27-38, 1990.

MARIN, A; BELL, M. The local/global integration of MNC subsidiaries and their technological behaviour: Argentina in the late 1990s. Research Policy, v. 39, n. 7, p. 919931, 2010 .

MAZO, M. S; TEIXEIRA, M. C; HERNANDES, C. A. Estratégia e globalização. In: Semead, 7, 2004. Anais. São Paulo: Semead, 2004.

MAZZOLA, H. J. Estratégias de empresas brasileiras na internacionalização de serviços de engenharia intensivos em conbecimento: estudo de caso. 2005. Dissertação de Mestrado em Administração, Pontifícia Universidade Católica de São Paulo, São Paulo, 2005.

MONTEIRO, L. F; ARVIDSSON, N; BIRKINSHAW, J. Knowledge flows within multinational corporations: explaining subsidiary isolation and its performance implications. OrganizationScience, v. 19, n. 1, p. 90-107, 2008.

MOORE, K. BIRKINSHAW, J. Managing knowledge in global service firms: Centers of excellence. Academy of Management Executive, Vol. 12. N. 4. Pennsylvania, 1998.

MOORE, K; BIRKINSHAW, J. Centers of excellence in global service firms. Knowledge Management Review. Disponível em: www.melcrum.com. Acesso em 02.03.1999.

MOROSINI, M. C. Estado do conhecimento sobre internacionalização de educação superior: conceitos e práticas. Education. Review, n. 28, p. 107-124, 2006.
PALMISANO, S. J. The globally integrated enterprise. Foreign Affairs, v. 85, n. 3, p. 127-136, 2006.

PAULSON, L. D. Service science: a new field for today's economy. IEEE Computer Society. Disponível em: www.computer. org. Acesso em 02.03.2006.

PEREIRA, L. V. Exportações de serviços comerciais brasileiros: desafios para a formulação de uma política comercial. Rio de Janeiro: BNDES, 2002.

PORTER, M. Vantagem competitiva: criando e sustentando um desempenho superior. Rio de Janeiro: Campus, 1989.

REZENDE, S. F. L. Internationalization process: an analytical framework. RAC, v. 7, n. 2, p. 137-156, 2003.

REZENDE, S. F. L. Multinationals and interdependence in internationalization processes. $R A C$, v.1, n. 1, p. 1-16, 2006.

REZENDE, S. F. L; VERSIANI, A. F. Em direção a uma tipologia de processos de internacionalização. RAE-Revista de Administração de Empresas, v. 50, n. 1, p. 24-36, 2010.

SCUMPARIM, D. Gestão de serviços globalmente integrada. In: Cíntia Barcelos. (Org.). Liderança e Tecnologia: 100 mini papers nos 100 anos da IBM. 1 ed. Rio de Janeiro: Obliq Press, 2011 , v. 1, p. $139-140$.

SCUMPARIM, D. e outros. A gestão de pessoas no modelo de gestão de serviços globalmente integrada: o caso de uma multinacional de TI. In: ENCONTRO NACIONAL DA ASSOCIAÇÃO NACIONAL DE PÓS-GRADUAÇÃO E PESQUISA EM ADMINISTRAÇÃO, 32, 2008, Rio de Janeiro. Anais. Rio de Janeiro: ANPAD, 2008.

SINHA, J. Global champions from emerging markets. The McKinsey Quarterly. Disponível em: www.mckinseyquarterly.com. Acesso em 02.03.2005.

SSME community. Services Sciences, Management and Engineering. http://www.research.ibm.com/ssme/. Acesso em 16.03.2008.

STÖTTINGER, B; SCHLEGELMICH, B. B. Explaining export development through psychic distance: enlightening or elusive? International Marketing Review, v. 15, n. 5, p. 357-372, 1998.

YIN, R. K. Case study research. California: Sage, 1994. 